\title{
NECROLOGICO
}

\section{JOÃO MOOJEN DE OLIVEIRA \\ (1904-1985)}

Hitoshi Nomura 1

Poucos pesquisadores se dedicaram ao estudo dos mamíferos no Brasil. Entre eles se destaca João Moojen de Oliveira, que se tornou especialista em sistemática de roedores e primatas, tendo também se dedicado às aves.

João Moojen de Oliveira - ou simplesmente João Moojen, como assinava seus artigos - era natural de Leopoldina, Minas Gerais, onde nasceu no dia $1^{\circ}$ de dezembro de 1904, tendo falecido no Rio de Janeiro, Rio de Janeiro, em 31 de março de 1985.

Moojen fez o curso secundário no Colégio Pedro II, entre 1918 e 1921. Em 1922 ingressou na Faculdade de Farmácia da Universidade do Brasil, concluindo o curso em 1925. De 1925 a 1932 foi professor de várias disciplina História Natural, Ciências Naturais, Física, Química, Francês, Inglês, Geometria, História do Brasil e da Civilização no Ginásio de Além-Paraíba, Minas Gerais, exercendo concomitantemente a profissão de farmacêutico. Ali casouse com D. Emília Costa Cruz Figueira, com a qual teve quatro filhos.

Em 1933 foi convidado para lecionar Biologia Geral e Zoologia na Escola Superior de Agricultura e Veterinária do Estado de Minas Gerais, em Viçosa. Esporadicamente lecionava Parasitologia e Entomologia. De agosto de 1933 até dezembro de 1937 foi chefe do Departamento de Biologia. Realizou diversas excursões para coleta de material zoológico, salientando-se a que realizou na Serra da Grama, Minas Gerais, de 14 a 21 de abril de 1935; no Distrito de São Miguel, Minas Gerais, de $1^{\circ}$ a 3 de novembro de 1935; e no Rio Matipoó e suas margens, Minas Gerais, de 2 a 16 de julho de 1936.

Seus dois primeiros artigos de 1935, um sobre "O pardal e o problema do povoamento ornitológico das cidades" no Jornal Minas Geraes, de 29 de setembro, página nove; o segundo sobre "Aves e pragas domesticas" na Folha Rural de Viçosa em novembro, página três. Em setembro de 1936 estréia em O Campo 7 (81): 13, tecendo considerações sobre duas aves, amigas do apicultor - o siriri, Tyrannus melancholicus, e o bemtevi, Pitangus maximiliani. Na edição de fevereiro de 1937 (O Campo 8 (865): 53-56), Moojen relata as observações que fez às margens do Rio Matipoó, afluente do Rio Doce, referentes às plantas,

1) Escola Superior de Agronomia Luiz de Queiroz, 13418-900 Piracicaba, São Paulo, Brasil. 
mamíferos, aves e peixes. Na edição de abril de 1938 (O Campo 9 (100): 17) ele estudou o valor econômico do chopim, Molothrus bonariensis, tendo examinado o conteúdo estomacal de 150 exemplares: apenas $2 \%$ mostraram restos de insetos, principalmente besouros; na época do amadurecimento do arroz seu estômago continha $100 \%$ dessa gramínea. Examinando 28 ninhos de tico-tico, Zonotrichia capensis, verificou que $75 \%$ continham ovos de chopin, propondo o combate a esse parasita pela destruição dos seus ovos.

Ainda em Viçosa, Moojen publicou quatro folhetos mimeografados, sem data. O primeiro sobre o preparo de mamíferos, o segundo sobre plantas, o terceiro sobre caça e pesca e o quarto sobre ofidismo.

Em 1938 Moojen exerceu o cargo de Professor-Chefe de História Natural do Colégio Universitário da Universidade do Brasil, tendo sido examinador no Concurso de Habilitação para a Faculdade Federal de Odontologia.

Ainda com a data de 1938 ele concluiu um artigo sobre tecelagem de colchas, observando o maquinário rústico e as operações de urdidura, em Viçosa, Minas Gerais, mas só publicado em 1942 (Bol. Mus. Nac. 14/17: 381393).

Requisitado pelo Ministério da Educação e Cultura, ingressou no Museu Nacional em 3 de janeiro de 1939. Prestou concurso com a monografia "As espécies brasileiras dos gêneros Echimys, Phyllomys e Cercomys (Echimyidae, Rodentia)" em junho de 1943, sendo então nomeado Naturalista da Divisão de Zoologia de Vertebrados e Invertebrados; de 20 de junho de 1941 até 23 de março de 1945 foi Chefe da Divisão de Zoologia e também em 19 de maio de 1948.

Em 1939 foi também Professor Catedrático, em comissão, da cadeira de Biologia Geral e Zoologia da Faculdade de Ciências da Universidade do Distrito Federal do Rio de Janeiro e, em 1940, Professor de Estudos de Roedores do Curso de Peste do Departamento Nacional de Saúde.

Em junho de 1939 a revista O Campo (10 (114):70), publicou suas observações sobre o morcego Diphylla ecaudata, que atacou ogalo, Gallus gallus domesticus.

Concluído em 16 de maio de 1939, o artigo "Ecogenização e domesticidade"só foi publicado em 1942 (Bol. Mus. Nac. 14/17: 83-127), no qual estudou o problema da domesticação animal por observação direta na natureza e no cativeiro. Segundo Moojen, os animais apresentam duas ordens de adaptação: a primeira é de caráter institintivo e específico, no qual o animal entra em contato íntimo com o meio, lá encontrando as condições necessárias para a vida; a segunda é de caráter individual, acomodando o animal aos fatores mesológicos não necessário à espécie, mas que interferem com as manifestações vitais do indivíduo. Moojen denominou de ecogenização "à acomodação das condições do meio à etologia animal".

Em 1940 ele foi nomeado membro do Conselho Nacional de Caça e Pesca para o estabelecimento de suas leis básicas e, em 1941, membro da Missão Abbink, encarregada de estudar a pesca no Brasil. 
Em 1940 encontramo-lo preocupado com alguns "Aspectos ecológicos do alto S. Francisco" (O Campo 11 (124): 22-24; 11 (127): 22-25; 11 (128): 57-58, 63) e em seguida, com o "Aspecto venatório do município de Campos" (Caça e Pesca 2 (17): 8-13; 2 (18): 8-13; 2 (19): 8-13, 43), quando estudou os hábitos de diversas espécies de aves que eram caçadas a tiro ou nos comedouros; observou também algumas espécies de mamíferos. Comentou Moojen que a região de Campos era excelente para a prática de caça e que "O problema de proteção à fauna, no Brasil, é um problema de conservação de habitat".

Entre 17 de fevereiro e 10 de março de 1940 ele participou da expedição conjunta do Museu Nacional com a comissão científica do Instituto Oswaldo Cruz, na zona da Estrada de Ferro Noroeste Brasil. As aves coligidas em Ilha Seca, São Paulo e Salobra, Mato Grosso, foram identificadas por Moojen (Mem. Inst. Osw. Cruz 35 (3): 660-668).

Especialista que era em caça, foi nomeado zoólogo do Conselho Nacional de Caça, exercendo essa função de 6 de março de 1940 até 1943.

Em 1941, em co-autoria com J.C.M. Carvalho e H.S. Lopes, publicou o artigo "Observações sobre o conteúdo gástrico das aves brasileiras" (Mem. Inst. Osw. Cruz 36 (3): 405-444), na maior parte fruto do estudo do material que ele coletou nos arredores de Viçosa de 1933 a 1938.

Em agosto de 1941 participou de uma excursão de coleta zoológica em Lagoa Feia, Rio de Janeiro; de 17 de novembro a 31 de dezembro de $1941 \mathrm{em}$ Foz do Iguaçu, Paraná e em Santa Catarina; de 7 de fevereiro a 4 de maio de 1942, nos rios São Francisco e Grande (Minas Gerais e Bahia).

Com data de 30 de janeiro de 1942 saiu o primeiro número da nova série do Bol. Mus. Nac., Zool., com 52 páginas, encerrando o seu trabalho:"Sobre os "Ciurídeos" das coleções do Museu Nacional, do Departamento de Zoologia de São Paulo e do Museu Paraense Emílio Goeldi", tratando dos esquilos, que no Brasil têm nomes vulgares de caxinguelês e coatipurus. Sobre esses animais publicou, no mesmo ano, algumas notas para o leigo no assunto (Fauna 1 (7): 3-4).

Ainda no mesmo ano, em co-autoria com Marcelo Silva Jr., preocupou-se com a relação existente entre a peste e os roedores silvestres (Arq. Hig. 12 (2): 145-167) e no Bol. Mus. Nac., n.s., Zool. 4: 121-125, publicou suas análises do conteúdo estomacal do anu-preto, Crotophaga ani. Ao contrário do que propalava a literatura científica da época, Moojen não encontrou nenhum carrapato (ácaro) no conteúdo estomacal dessa ave, apesar do grande número de exemplares que autopsiou.

Em 1943 publicou informações sobre "Alguns mamíferos colecionados no nordeste do Brasil" (Bol. Mus. Nac., n.s., Zool. 5: 1-19). Ainda no mesmo ano, na série A - $\mathbf{n}^{\circ} 1$ - Manuais do Museu Nacional - foi publicado o seu opúsculo "Captura e preparação de pequenos mamíferos para coleções de estudo" (Imprensa Nacional, Rio de Janeiro, 98p.), ampliando um folheto que publicara em Viçosa na década de 30. Esse opúsculo foi reproduzido nos seguintes números da revista Fauna: 1945 - 4 (2):12-16; 4 (3): 27-30; 4 (4): 15-18; 4 (6): 
20-22; 4 (8): 13-15; 4 (9): 17-21.

A convite do Departamento Nacional de Saúde ministrou uma aula de Entomologia Aplicada e Noções sobre Roedores no curso sobre Pestes, em 19 de janeiro de 1943.

Em 1943 publicou um estudo sobre a "Fauna de Minas Gerais - Aves" (Ceres 5 (26): 115-120). Esse material foi coletado de 1933 a 1938, nos arredores de Viçosa e identificado com auxílio de Alípio de Miranda Ribeiro.

De 1943 a 1945 Moojen foi zoólogo da Fundação Rockefeller. De 2 a 24 de agosto e de 12 a 22 de outubro de 1944, participou de uma excursão de estudos e coleta zoológica em Ilhéus, Bahia.

Na Revista do Museu Nacional, de curta duração (somente cinco números publicados), ele publicou os seguintes artigos de divulgação: em 1944 "Capivaras", 1 (1): 16 (reproduzido em 1945 em Caça e Pesca 5 (53): 18) e em 1945 - "Corrupião" 1 (3): 20.

Comtemplado com uma bolsa da John Simon Guggenheim Memorial Foundation, Moojen partiu para os Estados Unidos em 1945, para fazer o Curso de Doutorado em Filosofia na Universidade de Kansas, obtendo seu PhD com o trabalho "Speciation in the Brazilian spiny rats Genus Proechimys, family Echimyidae" em 1948 (Univ. Kansas Publ., Mus. Nat. Hist. 1 (19): 301-406), orientado pelo Prof. E. Raymond Hall, Diretor do Museu de História Natural e Chefe do Dapartamento de Zoologia da Universidade de Kansas. Nesse país tornou-se membro da Society of the Sigma XI for the Promotion of Research in Science (1947), da American Society of Mammalogists (1945), do Cooper Ornithological Club (1947) e da Phi Sigma Biological Society (1948). Durante quatro meses estudou Paleontologia no Arizona e no Colorado. Em 1948 foi convidado para lecionar mastozoologia sul-americana na Universidade de Kansas.

Em 1950 concluiu o Doutorado em História Natural pela Faculdade Nacional de Filosofia da Universidade do Brasil.

De 15 de dezembro de 1949 até 6 de janeiro de 1950 colecionou material zoológico no Amapá, e de 1950 a 1952 foi zoólogo do Jardim Zoológico do Rio de Janeiro.

Em 1950 publicou a descrição de uma nova espécie de roedor da família Echimyidae, Echimys (Phyllomys) kerri (Rev. Bras. Biol. 10 (4): 489-492) e observações sobre a identificação de um primata, Callithrix aurita (Rev. Bras. Biol. 10 (4): 491-502), que ele subdividiu em duas subespécies: C. a. aurita, do sudeste de Minas Gerais e baixas altitudes do Rio de Janeiro, e C. a. caelastis, das altas altitudes do Rio de Janeiro, Minas Gerais e São Paulo.

Aficcionado que era da caça, Moojen discorreu longamente sobre o pointer inglês, perdigueiro por excelência (Sel. Agric. 6 (66): 13-19; 6 (67): 27-34; 6 (68): 33-36); respectivamente em outubro, novembro e dezembro de 1951.

Em 1952 ele descreveu uma nova subespécie de roedor da família Echimyidae, Clyomys laticeps whartoni, do Paraguai (J. Wash. Acad. Sci. 42 (3): 102), salientando que foi o segundo registro da ocorrência desse gênero na 
América do Sul. Nesse mesmo ano o Instituto Nacional do Livro publicou, na séria A-2 - Biblioteca Científica Brasileira - o seu importante livro "Os Roedores do Brasil" (214p.) indispensável para a identificação das espécies relacionadas com pesquisas de medicina humana e animal. Nesse obra os roedores são divididos em: 1) arborícolas: ratos-de-taquara, Kannabateomys, Dactylomys; 2) rupícolas: mocó, Kerodon; 3) aquícolas: ratão-de-banhado, Myocastor; capivara, Hydrochoerus; cuíca ou rato-d'água, Nectomys; 4) galerícolas: rato-da-mata, capoeira ou campina, Akodon, Oxymicterus, Zygodontomys, Thaptomys; aratacu, Scapteromys e tuco-tuco, Ctenomys; 5) arvícolas: rato, Oryzomys, Thomasomys; 6) terrícolas: paca, Cuniculus, cotia, Dasyprocta, cotiara, Myoprocta, preá, Cavia e Galea.

Em 1954 ele publicou um artigo sobre a vida dos animais num zoológico (Caça e Pesca 11 (112): 33-34). No mesmo ano a Editora Kosmos publicou o livro de J.T. Descourtilz "História Natural das Aves do Brasil (Ornitologia Brasileira)", traduzido por Eurico Santos, com prefácio e anotações de João Moojen (dois volumes, 120p.); a segunda edição saiu em 1983, pela Editora Itatiaia (223p.). Moojen atualizou todos os nomes científicos das aves descritas nessa obra. Em 1956 ele preparou o texto em inglês de 48 pranchas coloridas desse mesmo autor, qua a Editora Kosmos publicou sob o título "Pageantry of Tropical Birds". Ainda em 1956 proferiu palestras no Museu Nacional sobre os ratos e a peste (19 de janeiro) e notas de uma excursão ao Amapá (20 de dezembro), tendo colaborado também com o Serviço Nacional de Endemias Rurais e orientado uma pesquisa de F.D.A. Pires sobre os cervídeos.

Em 1958 teve a oportunidade de descrever uma nova espécie de ciurídeo, Sciurus cabrerai (An. Ac. Bras, Ci. 30 (4): L-LI) e escreveu sobre "Alexandre Rodrigues Ferreira e a Zoologia" (INPA Publ. (3): 15-17), tecendo considerações sobre a viagem empreendida por esse famoso naturalista. Ele não falou do zoólogo e sim, da experiência negativa que Ferreira teve após tanto esforço em colecionar plantas, animais e minerais. Para Moojen "O contraste que representa o trabalho renhido de um naturalista, singularmente dotado, resistindo a vicissitudes incomuns, realizando integralmente uma etapa difícil de sua pesquisa - e o vazio final, é um fenômeno muito mais impressionante para mim do que fora talvez a positivação publicada de seus descobrimentos". No Amapá em 1956, Moojen capturou uma espécie nova de Sigmomys, que denominou $S$. alexandrei, em homenagem à memória desse naturalista.

De 1959 a 1962 foi encarregado pelo Governo Federal de organizar o Zôo-botânico de Brasília, tendo sido também Diretor do Departamento de Proteção à Natureza, de Brasília de 1959 a 1961. Em 1961 e 1962 foi Superintendente Geral da Agricultura do Distrito Federal, escolhido por técnicos em agronomia e veterinária.

Em 1965 descreveu um novo gênero e espécie de Cricetidae do Brasil Central, Juscelinomys candango (Rev. Bras. Biol 25 (3): 281-285), em homenagem ao fundador e trabalhadores de Brasília.

Em 1968 representou o Brasil no Simpósio Internacional de Estudos de 
Roedores e Ectoparasitos em Genebra e foi membro do Congresso Internacional de Alimentação Animal em Madri. Em 1969 a Escola de Agricultura do Estado de Minas Gerais, em Viçosa, convidou-o para ministrar cursos de Pós-graduação. Ainda neste ano foi participante do Simpósio sobre a Ação da Temperatura sobre os Animais Domésticos nessa mesma Escola.

$\mathrm{Na}$ Fundação Estadual de Engenharia do Meio Ambiente (FEEMA), Rio de Janeiro, foi Chefe do Serviço de Roedores em 1975. Em 1978 a Universidade de Brasília convidou-o para lecionar Mastozoologia, como Professor Titular e, em 1979, foi Professor Visitante Titular da Universidade Federal do Rio de Janeiro e examinador do concurso para Cátedra de Zoologia da Faculdade Nacional de Agronomia da Universidade do Brasil.

Como especialista em nutrição animal foi assessor de várias empresas privadas: Cia. Luz Steárica e Moinho da Luz em 1962, 1969 a 1971; Socil Pró-Pecuária, São Paulo, em 1965-1968; Anderson Clayton S.A., São Paulo, em 1968-1969; Industrial Irecê S.A., Bahia, de 1972 a 1975.

Em 1968 foi publicado o seu trabalho póstumo, em co-autoria com S.F. Reis e M.V. Dellape: "Quantitative variation in Trichomys apereoides (Lund, 1841) (Rodentia, Echimyidae) I. Non-geographic variation" (Bol. Mus. Nac., n.s., Zool. 316: 1-15).

Moojen foi colaborador da Chamber's Encyclopaedia, tendo escrito verbetes sobre mamíferos sul-americanos.

Vimos, então, que João Moojen de Oliveira foi muito ativo, tanto como pesquisador quanto como professor e assessor técnico. Durante suas inúmeras excursões pelo país colecionou cerca de 82000 exemplares de mamíferos, que hoje fazem parte do acervo do Museu Nacional do Rio de Janeiro.

Também contribuiu com o registro de nomes vulgares dos animais que estudou, material aproveitado pelos dicionaristas.

Seus colegas de profissão crismaram três gêneros, duas espécies e uma subespécie de animais com seus nome: PISCES - Characidae: Moojenichthys P.M. Ribeiro, 1956; OPILIONIDA - Gonyleptidae: Moojenia Mello Leirão, 1935; DIPLOPODA - Vanhoeffeniidae: Moojenodesmus Schubart, 1944; REPTILIA Viperidae: Bothrops moojeni Hoge, 1965; SCORPIONIDA - Bothriuridae: Bothriurus moojeni Mello Leitão, 1945; SCOLOPENDROMORPHA - Scolopendridae: Scolopendra angulata moojeni Bücherl, 1941.

AGRADECIMENTOS. Somos gratos à viúva de João Moojen de Oliveira, D. Emília Figueira Moojen de Oliveira, pelo fornecimento do curriculum vitae e de separatas dos trabalhos do homenageado.

Recebido em 30.XII.1991; aceito em 25.XI. 1993. 